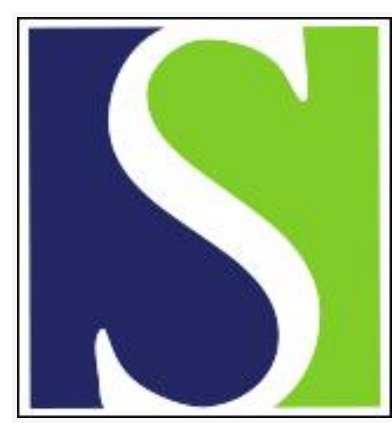

Scand J Work Environ Health 1989;15(2):125-129

https://doi.org/10.5271/sjweh.1878

Issue date: Apr 1989

Neurological and electroneuromyographic assessment of the adverse effects of acrylamide on occupationally exposed workers.

by He FS, Zhang SL, Wang HL, Li G, Zhang ZM, Li FL, Dong XM, Hu FR

Affiliation: Institute of Occupational Medicine, Chinese Academy of Preventive Medicine, Beijing.

This article in PubMed: www.ncbi.nlm.nih.gov/pubmed/2528204

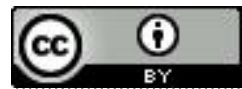




\title{
Neurological and electroneuromyographic assessment of the adverse effects of acrylamide on occupationally exposed workers
}

\author{
by Fengsheng He, MD, ${ }^{1}$ Soulin Zhang, MD, ${ }^{1}$ Huilan Wang, MB, ${ }^{2}$ Gang Li, MD, ${ }^{1}$
} Zheming Zhang, MB, ${ }^{1}$ Fengling Li, MB, ${ }^{2}$ Xiaoming Dong, MD, ${ }^{1}$ Furong $\mathrm{Hu}, \mathrm{MD}^{2}$

\begin{abstract}
HE F, ZHANG S, WANG H, LI G, ZHANG Z, LI F, DONG X, HU F. Neurological and electroneuromyographic assessment of the adverse effects of acrylamide on occupationally exposed workers. Scand $J$ Work Environ Health 1989;15:125-9. Seventy-one acrylamide workers and fifty-one unexposed referents were studied. Weak legs and numb hands and feet, preceded by skin peeling from the hands, were the early symptoms of the acrylamide workers; their early signs were impairment of vibration sensation in their toes and loss of ankle reflexes. Three cases had cerebellar involvement followed by polyneuropathy due to heavy exposure. Electroneuromyographic changes, including a decrease in the sensory action potential amplitude, neurogenic abnormalities in electromyography, and prolongation of the ankle tendon reflex latency, are of greater importance in the early detection of acrylamide neurotoxicity since they can precede the neuropathic symptoms and signs. The diagnostic criteria for occupational acrylamide intoxication of this study revealed three severe poisonings, six moderate poisonings, and 43 mild poisonings. The total prevalence of acrylamide poisoning was $73.2 \%$. The prevention of dermal exposure to acrylamide should be emphasized.
\end{abstract}

Key terms: acrylamide intoxication, cerebellar dysfunction, polyneuropathy, vibration sensation impairment.

Acrylamide is the raw material mainly used in the production of polyacrylamides, which are useful as flocculants or grouting agents. Since 1953, monometric acrylamide has been known as a neurotoxicant to man (1). A total of 61 cases of acrylamide intoxication was reported among humans outside China between 1957 and $1977(1-11)$. However, more than 90 cases of acrylamide intoxication have occurred in China in the past five years due to an increase in the exposure to acrylamide in a number of small townshiprun or village-owned industries. This study was carried out for the purpose of assessing the adverse effects of acrylamide on occupationally exposed workers in small factories manufacturing acrylamide.

\section{Subjects and methods}

\section{Exposure}

In the factory under study the production of acrylamide and its polymers began in May 1984. Acrylamide monomer $(27-30 \%)$ was prepared by the hydration of acrylonitrile, flash vaporization, and condensation. It then underwent the ion-exchange process, followed by polymerization. The atmospheric concentrations of

\footnotetext{
1 Institute of Occupational Medicine, Chinese Academy of Preventive Medicine, Beijing, People's Republic of China.

2 Department of Occupational Medicine, Qilu Petrochemical Industry Hospital, Shandong, People's Republic of China.
}

Reprint requests to: Professor F He, Institute of Occupational Medicine, Chinese Academy of Preventive Medicine, 29 Nan Wei Road, Beijing, People's Republic of China. acrylamide, determined by gas chromatography, reached $5.56-9.02 \mathrm{mg} / \mathrm{m}^{3}$ during polymerization when there was an exceptional increase of production between March and June 1985 and then decreased to $0.0324 \mathrm{mg} / \mathrm{m}^{3}$ on the average after renovation of the workshop in July 1985 . Heavy skin contamination by aqueous acrylamide monomer on the hands was common among the exposed workers because of inadequate personal protection, unawareness of acrylamide toxicity, and unsatisfactory personal hygiene. The acrylamide content of the water in which three workers had washed their hands was $410 \mathrm{mg} / \mathrm{l}$. The acrylamide workers worked for $8 \mathrm{~h} / \mathrm{d}, 6 \mathrm{~d} /$ week.

\section{Subjects}

Seventy-one workers exposed to acrylamide ( 45 men and 26 women) were studied in October 1985. Their ages ranged between 17 and 41 (mean 24) years, and they had been exposed from 1 to 18 months. Fifty-one unexposed blue-collar workers from the same town ( 33 men and 18 women) between the ages of 17 and 35 (mean 23) years served as the reference group. None of the referents suffered from nervous diseases. Diabetes was excluded from both groups.

\section{Methods}

Clinical and laboratory examinations. All the subjects of both groups were interviewed with the aid of a structured questionnaire obtaining information on demographic factors, occupational history, symptoms, past illnesses, and family history. Physical and neurological examinations, visual acuity, and visual field test- 
ing, skin temperature measurement, electrocardiography, and electroencephalography were performed. The laboratory studies included routine blood and urine tests, liver function (serum glutamate pyruvate transaminase and the thymol turbidity test), serum hepatitis $B$ surface antigen, serum $\beta$-glucuronidase, and immunoglobins (IgG, IgA, IgM).

Electroneuromyographic examination. The electroneuromyographic (ENMG) examination was carried out with a DISA 1500 electromyographic (EMG) apparatus. The electrical activities of the abductor pollicis brevis muscles and abductor digiti minimi muscles, including the insertion activity, spontaneous activity of motor units, and the electrical activity during mild and maximal voluntary contraction, were recorded with concentric needle electrodes. The mean duration and mean voltage of 20 motor unit potentials and the percentage of polyphasic potentials in each muscle were determined. The duration of a motor unit was taken as the time for the oscilloscope tracing to return to the base line after its original deflection from the beginning of that potential. The voltage of a motor unit was taken as the peak-to-peak amplitude. The phase of a motor unit potential was defined by the number of deflections across the base line.

The minimum acceptable skin temperature of the hands and feet during the measurements of nerve conduction velocity and distal latency was $30^{\circ} \mathrm{C}$. Bipolar skin stimulation electrodes were used in all the measurements of nerve conduction velocity. Voltage was always $30 \%$ supramaximal. For measuring maximal motor nerve conduction velocity (MCV), the median and ulnar nerves were stimulated at the elbow and wrist, and the muscle action potential was recorded from the abductor pollicis brevis muscle and the abductor digiti minimi muscle with concentric needle electrodes. The peroneal nerve was stimulated at the knee and ankle, and the muscle action potential was recorded from the extensor digitorum brevis muscle by surface electrodes.

Table 1. Symptoms of the acrylamide workers and the reference group.

\begin{tabular}{|c|c|c|c|c|}
\hline \multirow[t]{2}{*}{ Symptoms } & \multicolumn{2}{|c|}{$\begin{array}{c}\text { Acrylamide } \\
\text { group } \\
(\mathrm{N}=71)\end{array}$} & \multicolumn{2}{|c|}{$\begin{array}{c}\text { Reference } \\
\text { group } \\
(\mathrm{N}=51)\end{array}$} \\
\hline & $N$ & $\%$ & $\mathrm{~N}$ & $\%$ \\
\hline Skin peeling from the hands & 38 & $53.5^{*}$ & 2 & 3.9 \\
\hline Numbness in the hands and feet & 15 & $21.1^{*}$ & 2 & 3.9 \\
\hline Lassitude & 14 & $19.7^{* *}$ & 1 & 1.9 \\
\hline Sleepiness & 12 & $16.9^{* *}$ & - & 0 \\
\hline Muscle weakness & 11 & $15.4^{* *}$ & - & 0 \\
\hline Clumsiness of the hands & 8 & $11.2^{\star}$ & - & 0 \\
\hline Anorexia & 8 & $11.2^{*}$ & 1 & 1.9 \\
\hline Unsteady gait & 6 & $8.4^{\star}$ & - & 0 \\
\hline Coldness of the hands and feet & 6 & $8.4^{*}$ & - & 0 \\
\hline Difficulty in grasping & 5 & $7.0^{\star}$ & - & 0 \\
\hline Stumbling and falling & 5 & $7.0^{*}$ & - & 0 \\
\hline Sweating & 27 & 38.0 & 14 & 27.4 \\
\hline Dizziness & 7 & 9.8 & 2 & 3.9 \\
\hline Cramping pain & 6 & 8.4 & 5 & 9.8 \\
\hline
\end{tabular}

* $P<0.05,{ }^{*} P<0.01$ ( $X^{2}$ test).
The sensory nerve conduction velocity (SCV) of the median and ulnar nerve was measured through the stimulation of the forefinger and the little finger, respectively, with ring electrodes, recordings being made at the wrist and elbow by surface electrodes. The sensory nerve conduction velocity of the sural nerve was recorded with a surface electrode at midcalf, $14 \mathrm{~cm}$ from the stimulating electrode placed just below the lateral malleolus. The peak-to-peak amplitude of the evoked potentials was also measured.

The H-reflex was recorded from the soleus muscle from stimulation of the tibial nerve at the popliteal fossa. The ankle tendon reflex was elicited by a mechanical tap on the Achilles tendon with a reflex hammer fitted to trigger the oscilloscope; it was recorded from the medial head of the gastrocnemius muscle when the subjects were supine with their knees semiflexed at about $120^{\circ}$.

Statistical methods. The chi-square test was used to analyze the symptoms and signs, and the Student's t-test was used in the analysis of electroneuromyographic parameters.

\section{Results}

\section{Symptoms}

The initial symptoms were the peeling of skin and excessive sweating of the hands, mainly due to topical contamination by aqueous acrylamide. Muscle weakness of the legs, as well as numbness and tingling of the hands and feet, indicating an involvement of the peripheral nervous system, appeared in one-fifth of the exposed subjects after 3-10 months of exposure. Nine workers who were engaged in the ion-exchange and the polymerization of acrylamide during March and April 1985 developed lassitude, sleepiness, anorexia, and loss of body weight a month later and progressed to inability to hold things tightly, unsteadiness in walking, and difficulties in lifting their legs when climbing stairs and in standing with their eyes closed or while washing their faces. Three of the nine were found to have horizontal nystagmus, truncal ataxia, and clumsiness of the hands when they were admitted to the hospital in May 1985. They showed improvement of cerebellar function a month later, but began losing their sensation of vibration and tendon reflexes. [Such a clinical course agrees with the typical features of severe acrylamide poisoning in which peripheral neuropathy always develops after the involvement of the cerebellum (8).] When these persons were interviewed in October 1985 in this study, they had recovered considerably after removal of exposure for three to five months. No disturbance of consciousness or symptoms other than those of the nervous system were noted. The comparison of the prevalence of symptoms between the acrylamide workers and the reference group is shown in table 1. 


\section{Signs}

In addition to the erythema and skin peeling of the hands the impairment of vibration sensation, a diminution of tendon reflexes, and a positive Romberg's sign were the most prominent signs in 27 acrylamide workers, ie, in $38 \%$ of the exposed group. The sensory function and tendon reflexes were more involved in the distal part of the extremities. Distal muscular strength decreased to grade 3-4 of the scale of the Medical Research Council in one-fifth of the exposed workers. The distal skin temperatures were also lower in the exposed subjects than in the reference group (table 2). [These neurological signs are consistent with a distal polyneuropathy with more involvement of deep sensation.] Visual acuity and the visual field were normal. No other signs were seen in either group.

\section{Electroneuromyographic changes}

Sixty-nine workers of the acrylamide group and 48 unexposed referents were studied by ENMG. Only three acrylamide workers showed denervation potentials (fibrillations in two, positive waves in one). A discrete pattern of recruitment was noted for nine acrylamide workers. However, a prolonged duration of motor unit potentials and an increase in the number of polyphasic potentials were found in 40 and 29 of the acrylamide workers, respectively, including 25 acrylamide workers without any neuropathic signs such as impairment of distal sensation or reflexes (tables 3 and 4). [This finding suggests that a partial denervation of the distal muscles caused by axonal degeneration of the peripheral nerves could be a subclinical abnormality in acrylamide workers.]

The H-reflex and the ankle tendon reflex were nonresponsive in $23(33.3 \%)$ and $21(30.4 \%)$ of the acrylamide workers, respectively, whose ankle reflexes were diminished or absent. The latency of a detectable ankle tendon reflex was significantly prolonged in 48 acrylamide workers, including those with no clinical neurological findings, in comparison with that of the reference group when the heights were adjusted by the analysis of covariance. However, a prolongation of the detectable H-reflex latency was only seen in the acrylamide workers with neuropathic signs (table 5). [This finding could well be explained by the fact that a degeneration of primary annulospiral endings of muscle spindles and secondary muscle spindle endings has been demonstrated prior to nerve fiber degeneration and clinical signs in acrylamide-intoxicated animals $(11,12)$.] Therefore, the latency of the ankle tendon reflex seems to be more sensitive than the $\mathrm{H}$ -

Table 2. Signs of the acrylamide workers and the reference group.

\begin{tabular}{|c|c|c|c|c|}
\hline \multirow[t]{2}{*}{ Signs } & \multicolumn{2}{|c|}{$\begin{array}{c}\text { Acrylamide } \\
\text { workers } \\
(\mathrm{N}=71)\end{array}$} & \multicolumn{2}{|c|}{$\begin{array}{c}\text { Reference } \\
\text { group } \\
(\mathrm{N}=51)\end{array}$} \\
\hline & $N$ & $\%$ & $\mathrm{~N}$ & $\%$ \\
\hline Erythema of hands & 16 & $22.5^{\star \star}$ & - & 0 \\
\hline Skin peeling from the hands & 16 & $22.5^{* *}$ & 1 & 1.9 \\
\hline \multicolumn{5}{|l|}{ Sensory impairments } \\
\hline $\begin{array}{l}\text { Vibration sensation } \\
\text { Pain sensation } \\
\text { Touch sensation } \\
\text { Position sensation }\end{array}$ & $\begin{array}{r}12 \\
7 \\
6 \\
1\end{array}$ & $\begin{array}{l}16.9^{* *} \\
9.8^{*} \\
8.4^{*} \\
1.4\end{array}$ & $\begin{array}{l}- \\
z \\
-\end{array}$ & $\begin{array}{l}0 \\
0 \\
0 \\
0\end{array}$ \\
\hline Muscle atrophy in hands & 4 & 5.6 & - & 0 \\
\hline \multicolumn{5}{|l|}{ Diminished reflexes } \\
\hline $\begin{array}{l}\text { Biceps } \\
\text { Triceps } \\
\text { Knee } \\
\text { Ankle }\end{array}$ & $\begin{array}{r}12 \\
10 \\
11 \\
8\end{array}$ & $\begin{array}{l}16.9^{* *} \\
14.0 \\
15.4^{*} \\
11.2^{*}\end{array}$ & $\begin{array}{r}- \\
4 \\
1 \\
1\end{array}$ & $\begin{array}{l}0 \\
7.8 \\
1.9 \\
1.9\end{array}$ \\
\hline \multicolumn{5}{|l|}{ Loss of reflexes } \\
\hline $\begin{array}{l}\text { Biceps } \\
\text { Triceps } \\
\text { Knee } \\
\text { Ankle }\end{array}$ & $\begin{array}{r}3 \\
5 \\
5 \\
17\end{array}$ & $\begin{array}{c}4.2 \\
7.0 \\
7.0^{*} \\
23.9^{* *}\end{array}$ & $\begin{array}{l}\overline{1} \\
- \\
-\end{array}$ & $\begin{array}{l}0 \\
1.9 \\
0 \\
0\end{array}$ \\
\hline Intention tremor & 13 & $18.3^{*}$ & 2 & 3.9 \\
\hline Positive Romberg's sign & 15 & 21.1 & 3 & 5.8 \\
\hline
\end{tabular}

* $P<0.05,{ }^{*} * P<0.01$ ( $X^{2}$ test).

Table 3. Prevalence of electromyographic abnormalities.

\begin{tabular}{lcc}
\hline & $\begin{array}{c}\text { Acrylamide Reference } \\
\text { group } \\
(\mathrm{N}=69)\end{array}$ & $\begin{array}{c}\text { group } \\
(\mathrm{N}=48)\end{array}$ \\
\cline { 2 - 3 } & - & - \\
Prolonged insertional activity & 2 & - \\
Spontaneous potentials & 1 & - \\
$\quad$ Fibrillation & 40 & 4 \\
$\quad$ Positive wave & 29 & - \\
Prolonged duration of motor units & 9 & - \\
Increased polyphasic potentials & & \\
Discrete pattern of recruitment & & \\
\hline
\end{tabular}

a Number of muscle samples 138.

b Number of muscle samples 96 .

Table 4. Comparison of the mean duration and amplitude of the motor unit potentials of the studied groups.

\begin{tabular}{|c|c|c|c|c|c|}
\hline \multirow{2}{*}{ Group } & \multirow{2}{*}{$\begin{array}{l}\text { Number of } \\
\text { subjects }\end{array}$} & \multicolumn{2}{|c|}{$\begin{array}{l}\text { Abductor pollicis brevis } \\
\text { muscle }\end{array}$} & \multicolumn{2}{|c|}{$\begin{array}{l}\text { Abductor digiti minimi } \\
\text { muscle }\end{array}$} \\
\hline & & $\begin{array}{c}\text { Mean duration } \\
(\mathrm{ms})\end{array}$ & $\begin{array}{l}\text { Mean amplitude } \\
(\mu \mathrm{v})\end{array}$ & $\begin{array}{l}\text { Mean duration } \\
\text { (ms) }\end{array}$ & Mean amplitude \\
\hline Acrylamide & 69 & $9.3^{* *}$ & $332.2^{*}$ & $9.8^{* *}$ & $365.6^{\star *}$ \\
\hline $\begin{array}{l}A \\
B\end{array}$ & $\begin{array}{l}27 \\
42\end{array}$ & $\begin{array}{l}9.4^{* \star} \\
9.1^{\star}\end{array}$ & $\begin{array}{l}340.2^{*} \\
319.9\end{array}$ & $\begin{array}{l}9.8^{* *} \\
9.6^{\star *}\end{array}$ & $\begin{array}{l}420.1^{* *} \\
342.2^{* *}\end{array}$ \\
\hline Reference & 48 & 8.5 & 291.7 & 8.8 & 290.9 \\
\hline
\end{tabular}

a $A=$ exposed subjects with neuropathic signs, $B=$ exposed subjects without neuropathic signs.

* $\mathrm{P}<0.05,{ }^{*} \mathrm{P}<0.01$ (compared with the reference group by Student's $\mathrm{t}$-test). 
Table 5. Comparison of the H-reflex and ankle tendon reflex latencies (ms) of the studied groups.

\begin{tabular}{|c|c|c|c|c|c|c|c|c|c|}
\hline \multirow{3}{*}{ Group } & \multirow{3}{*}{$\begin{array}{l}\text { Number } \\
\text { of } \\
\text { subjects }\end{array}$} & \multicolumn{4}{|c|}{$\mathrm{H}$-reflex } & \multicolumn{4}{|c|}{ Ankle tendon reflex } \\
\hline & & \multirow{2}{*}{$\begin{array}{l}\text { Nonresponsive } \\
\text { (N) }\end{array}$} & \multicolumn{3}{|c|}{ Detectable Iantency } & \multirow{2}{*}{$\begin{array}{c}\text { Nonresponsive } \\
(\mathrm{N})\end{array}$} & \multicolumn{3}{|c|}{ Detectable latency } \\
\hline & & & $\mathrm{N}$ & Mean & SD & & $\mathrm{N}$ & Mean & SD \\
\hline Acrylamide ${ }^{a}$ & 69 & 23 & 46 & 27.8 & 1.8 & 21 & 48 & $33.6^{*}$ & 2.9 \\
\hline $\begin{array}{l}\mathrm{A} \\
\mathrm{B}\end{array}$ & $\begin{array}{l}27 \\
42\end{array}$ & $\begin{array}{r}18 \\
5\end{array}$ & $\begin{array}{r}9 \\
37\end{array}$ & $\begin{array}{l}29.1^{*} \\
27.5\end{array}$ & $\begin{array}{l}1.6 \\
1.8\end{array}$ & $\begin{array}{r}17 \\
4\end{array}$ & $\begin{array}{l}10 \\
38\end{array}$ & $\begin{array}{l}35.8^{*} \\
33.2^{\star}\end{array}$ & $\begin{array}{l}2.7 \\
2.8\end{array}$ \\
\hline Reference & 46 & 0 & 46 & 27.8 & 1.9 & 0 & 46 & 32.5 & 2.5 \\
\hline
\end{tabular}

a $A=$ exposed subjects with neuropathic signs, $B=$ exposed subjects without neuropathic signs.

* $P<0.01$ (compared with the reference group by an analysis of covariance to adjust the heights).

Table 6. Comparison of the sensory action potential amplitudes $(\mu v)$ of the studied groups.

\begin{tabular}{|c|c|c|c|c|c|c|c|c|c|c|c|}
\hline \multirow{3}{*}{ Group } & \multirow{3}{*}{$\begin{array}{l}\text { Number of } \\
\text { subjects }\end{array}$} & \multicolumn{4}{|c|}{ Median nerve } & \multicolumn{4}{|c|}{ Ulnar nerve } & \multirow{2}{*}{\multicolumn{2}{|c|}{ Sural nerve }} \\
\hline & & \multicolumn{2}{|c|}{ Wrist } & \multicolumn{2}{|c|}{ Elbow } & \multicolumn{2}{|c|}{ Wrist } & \multicolumn{2}{|c|}{ Elbow } & & \\
\hline & & Mean & SD & Mean & SD & Mean & SD & Mean & SD & Mean & SD \\
\hline Acrylamide $^{a}$ & 69 & $9.3^{* *}$ & 2.1 & 3.8 & 1.8 & $6.8^{* *}$ & 2.0 & 4.8 & 1.9 & $6.6^{*}$ & 1.9 \\
\hline $\begin{array}{l}A \\
B\end{array}$ & $\begin{array}{l}27 \\
42\end{array}$ & $\begin{array}{l}6.0^{\star *} \\
11.1\end{array}$ & $\begin{array}{l}2.3 \\
1.8\end{array}$ & $\begin{array}{l}2.9^{\star} \\
4.2\end{array}$ & $\begin{array}{l}1.9 \\
1.7\end{array}$ & $\begin{array}{l}4.9^{\star *} \\
8.4\end{array}$ & $\begin{array}{l}2.2 \\
1.7\end{array}$ & $\begin{array}{l}3.7^{\star \star} \\
5.9\end{array}$ & $\begin{array}{l}2.2 \\
1.6\end{array}$ & $\begin{array}{l}4.9^{*} \\
8.1\end{array}$ & $\begin{array}{l}1.9 \\
1.9\end{array}$ \\
\hline Reference & 48 & 12.3 & 1.6 & 4.2 & 1.6 & 9.4 & 1.7 & 5.6 & 1.6 & 8.8 & 1.8 \\
\hline
\end{tabular}

a $A=$ exposed subjects with neuropathic signs, $B=$ exposed subjects without neuropathic signs.

* $\mathrm{P}<0.05,{ }^{\star \star} \mathrm{P}<0.01$ (compared with the reference group by the Student's t-test).

reflex latency in the early detection of acrylamide toxicity in humans.

The results of the motor and sensory nerve conduction measurements did not show much difference between the two groups, except for a mild slowing in the motor nerve conduction velocity of the peroneal nerve in the acrylamide group $[42.8(\mathrm{SD} 1.12) \mathrm{m} / \mathrm{s}]$ in comparison with the reference group [44.9 (SD 1.17) $\mathrm{m} / \mathrm{s}]$. However, the sensory action potentials of the median, ulnar, and sural nerves were decreased significantly in the acrylamide workers with neurological signs as compared with those of the reference group (table 6). [These findings are in accordance with the results of previous reports $(4,10,13)$ suggesting that the defect in the sensory action potential results from the axonopathy of sensory nerve fibers and that the peripheral sensory nerves are more severely damaged than the associated motor nerves $(4,10)$.]

\section{Other laboratory tests}

The serum $\beta$-glucuronidase, serum immunoglobulin, and routine urine tests were normal. A blood leucocyte count of less than $4000 / \mathrm{mm}^{3}$ was found for three acrylamide workers, and an elevated serum glutamate pyruvate transaminase in one. Only one out of the 41 electroencephalograms of the acrylamide group showed a mild abnormality, and three showed marginal findings. The electrocardiography showed five cases of sinus arrhythmia and 10 cases of sinus bradycardia among the 71 acrylamide workers, whereas these two abnormalities were found in 3 and 7 , respectively, of the 51 referents, the difference between the two groups not being significant.

\section{Discussion}

The results of this study clearly indicate that the adverse effects of acrylamide from chronic industrial exposure are mainly damage to the peripheral nervous system, while heavy exposure to acrylamide induces cerebellar dysfunction followed by polyneuropathy. The early symptoms of acrylamide neuropathy include muscular weakness of the legs and numbness of the hands and feet, usually preceded by skin peeling from the hands, and the early signs are the impairment of vibration sensation in the toes and the loss of ankle reflexes. However, the ENMG changes, including the prolongation of the duration of the motor unit potentials and the prolonged ankle tendon reflex latency, as well as a decrease in the sensory action potential amplitude, are of greater importance in the early detection of acrylamide neurotoxicity in workers, as they can appear prior to the clinical symptoms or signs.

On the basis of available data and previous clinical reports $(1-8,10)$, we propose the following diagnostic criteria for occupational acrylamide poisoning: (i) verified exposure to acrylamide; (ii) reasonable exclusion of other diseases; and (iii) evidence of symptoms, signs, and ENMG changes indicating polyneuropathy in mild and moderate cases of intoxication and cerebellar involvement in cases of severe intoxication. Mild intoxication can be characterized as skin peeling from the hands, weakness, and tingling or numbness in the 
extremities with distal, symmetrical sensory (mainly vibration sensation) impairment or diminished ankle reflexes or neurogenic ENMG abnormalities without the presence of spontaneous denervation potentials. Moderate intoxication would involve similar but severer symptoms than mild intoxication, sensory deficits progressing to the level of the elbows and knees, with a positive Romberg's sign or with complete loss of ankle reflexes or muscular atrophy, and ENMG abnormalities consisting of fibrillation and positive sharp waves. Severe intoxication would appear as symptoms such as lassitude, sleepiness, loss of body weight, clumsiness of the hands, and unsteady gait; ataxia, nystagmus and positive Romberg's sign; and evidence of polyneuropathy which can appear about two weeks later than the onset of cerebellar dysfunction. According to the aforementioned diagnostic criteria, 43 workers in the acrylamide group were diagnosed as being mildly intoxicated by acrylamide; this group included 25 cases who had only ENMG evidence of neuropathy without any neurological signs. Six workers were moderately intoxicated. Three had severe acrylamide intoxication with partial recovery of cerebellum involvement. The total prevalence of occupational acrylamide poisoning was $73.2 \%$ in the exposed group.

Most of the workers diagnosed as suffering from occupational acrylamide intoxication in this study had been involved in the ion-exchange and polymerization of acrylamide; they handled a $27-30 \%$ aqueous solution of acrylamide monomer. Their exposure to aqueous acrylamide of higher concentration has indicated that dermal contact may have been the main route of exposure although the possible inhalation of aerosol or vapors cannot be ruled out. Since, so far, there have been no quantitative methods available for determining human acrylamide exposure, it is essential to use ENMG as a tool for the early assessment of the adverse effects of acrylamide in exposed workers. Alternatively, quantitative assessment of vibration sensation offers considerable promise as another sensitive and easily applicable method for monitoring the health of acrylamide workers. In addition, preventive measures such as the enclosure of production procedures and the wearing of protective clothing should be applied to protect the exposed population. Hygienic educational strategies for the workers are also a necessity to minimize dermal exposure.

\section{Acknowledgments}

The authors are indebted to many of their colleagues of Qilu Petrochemical Industry Hospital for their kind help with this study. The technical work was assisted in part by Mr Yu, Ms X Jiao, and Mr J Zhang of the Institute of Occupational Medicine.

\section{References}

1. WHO Task Group. Acrylamide. Geneva: World Health Organization, 1985. (Environmental health criteria 49.)

2. Auld RB, Bedwell SF. Peripheral neuropathy with sympathetic overactivity from industrial contact with acrylamide. Can Med Assoc J 1967;96:652-4.

3. Davenport JG, Farrell PR, Sumi SM. "Giant axonal neuropathy" caused by industrial chemicals: neurofilamentous axonal masses in man. Neurology 1976; 26:919-23.

4. Fullerton PM. Electrophysiological and histological observations on peripheral nerves in acrylamide poisoning in man. J Neurol Neurosurg Psychiatry 1969;32: $186-92$.

5. Garland TO, Patterson MWH. Six cases of acrylamide poisoning. Br Med J 1967;4:134-8.

6. Igisu H, Goto I, Kawamura Y, Kato M, Izumi D, Kuroiwa $\mathrm{Y}$. Acrylamide encephaloneuropathy due to well water pollution. J Neurol Neurosurg Psychiatry 1975; 38:581-4.

7. Kesson CM, Lawson DH, Baird AW. Acrylamide poisoning. Postgrad Med J 1977;53:16-7.

8. Le Quesne PM. Acrylamide. In: Spencer PS, Schaumburg $\mathrm{HH}$, ed. Experimental and clinical neurotoxicology. Baltimore, Maryland: Williams \& Wilkins Company, 1980:309-25.

9. National Institute for Occupational Safety and Health. Criteria for a recommended standard - occupational exposure to acrylamide. Washington, DC: National Institute for Occupational Safety and Health, 1976.

10. Takahashi M, Ohara T, Hashimoto K. Electrophysiological study of nerve injuries in workers handling acrylamide. Int Arch Arbeitsmed 1971;28:1-11.

11. Prineas J. The pathogenesis of dying-back polyneuropathies: II. an ultrastructural study of experimental acrylamide intoxication in the cat. J Neuropathol Exp Neurol $1969 ; 28: 598-621$.

12. Schaumburg $\mathrm{HH}$, Wisniewski HM, Spencer PS. Ultrastructural studies of the dying-back process: 1. peripheral nerve terminal and axon degeneration in systemic acrylamide intoxication. J Neuropathol Exp Neurol 1974; $33: 260-84$

13. Sumner AJ, Asbury AK. Acrylamide neuropathy: selective vulnerability of sensory fibres. Trans Am Neurol Assoc 1974;99:79-_.83.

Received for publication: 1 September 1988 